\title{
Foreword and acknowledgements
}

Entrepreneurship as Social Change is the third book in a miniseries of four publications called Movements in Entrepreneurship. The journey from a socalled writers' workshop to a publishable manuscript is a collective process wherein the quality of dialogue and conversation needs to develop into a focused and enriched book. A new movement in the field of entrepreneurship - in this case social entrepreneurship - is taken up for the purpose of a critical and crucial discussion that does not reproduce just more of the same (entrepreneurship), but rather creates a chance to change our understanding of entrepreneurship itself. Whether this book succeeds in accomplishing such a movement, we will leave up to the interested and critical readers. This cannot prevent us from acknowledging the committed efforts of many direct and indirect contributors that have made the transition from workshop to book a smooth and worthwhile endeavour.

With the theme of the 'earth' - after the ones of water (see New Movements in Entrepreneurship, Steyaert and Hjorth, 2003) and air (see Narrative and Discursive Approaches in Entrepreneurship, Hjorth and Steyaert, 2004) - we entered the site of the small and beautiful village of Tällberg, Sweden. The village resides on a slope looking down on Lake Siljan. Lake Siljan is one reminder of the third largest meteorite impact in our planet's history. Around 360 million years ago, a 4-km large meteor fell from space and had an enormous impact on the Earth here, making it a worthy place to explore the groundings of entrepreneurship. Close to Tällberg, we visited the extraordinary festival stage of Dalhalla, a former limestone quarry. The open mining in this area has created a natural amphitheatre $-400 \mathrm{~m}$ long, $175 \mathrm{~m}$ wide and 60 $m$ deep. How this performance arena came about offers an excellent illustration of cultural entrepreneurship as social change, which was shared with the workshop participants through the intriguing story told by Per Frankelius (University of Örebro). We are grateful for his contribution. Furthermore, Ellen O'Connor (University of Paris Dauphine) and Tor Hernes (Norwegian School of Management BI) gave excellent keynotes to stimulate discussions. We would also like to thank all participants in the workshop including those whose contributions did not make it into the book. Many of the participants acted also as valuable reviewers for the papers of other authors during and after the workshop. We also acknowledge the valuable contribution of the external (anonymous) reviewers who helped us in sharpening the arguments of 
the different chapters. In particular, we would like to thank Magnus Aronsson who, as director of ESBRI, organized a flawless workshop event that made the whole experience pleasant and socially stimulating. The publisher Edward Elgar - especially Francine O'Sullivan and Jo Betteridge - have responded with patience and enthusiasm, two rare qualities that we value considerably in this cooperation. Finally, the editors' special 'thanks' go to Pascal Dey, whose intellectual and practical support in preparing the final manuscript has been invaluable.

Keep looking at the 'Movements', Chris and Daniel 